\title{
COMMENTARY
}

\section{Unintended consequences: what of quality outside the QOF?}

For over a decade general practice has been subject to increasing levels of governance, guidelines, incentives, and targets - what one professor of primary care has referred to as the 'industrialisation' of family medicine. ${ }^{1}$ A key step-change in this came with the introduction of the new GMS contract and Quality and Outcomes Framework (QOF) in 2004. For the first time, a significant proportion (typically around $20 \%$, but in some cases up to one-third) of general practice income was linked to performance - predominantly against biomedical indicators of quality of care, but also practice organisation, the provision of additional services and, to a lesser degree, attention to patient experience.

Gillies et al's learning journey reveals an underlying disquiet with such trends; and with the QOF in particular. ${ }^{2}$ While recognising the framework's potential to improve individual and population health, the authors cite 'growing anxieties that the focus on the QOF, driven by financial incentives, may lead to the loss of something important but hard to measure in general practice'. Their concerns are widespread and justified. ${ }^{3}$

Looking purely at biomedical indicators of quality included in the QOF, the evidence suggests that GPs have been working to higher standards since its introduction, and for some indicators a causal relationship is likely. General practice returned an average of $91.3 \%$ of the maximum possible score on the QOF in the first year (2004/05), rising to $96.8 \%$ in $2007 / 08$; significantly higher than was anticipated by the Department of Health. Concomitant with this there have been real step-changes in clinical quality for patients with certain chronic diseases, such as asthma and diabetes (though not $\mathrm{CHD}$ ); ${ }^{4}$ and inequality in practice performance has fallen, with faster improvement in practices in the most deprived quintile reducing the difference in relation to the least deprived from $4.0 \%$ to $0.88 \%{ }^{5}{ }^{5}$

However, as Gillies et al's study shows, there is more to general practice than simply hitting QOF targets: we should always be concerned with the net effect of the framework. Quality of care is hard to conceptualise and measure in ways which capture the full range of issues that matter to patients and can be applied day-to-day. While 'hard' endpoints of care are incredibly important, follow the framework too rigidly and the consultation soon becomes an inhuman exercise in ticking boxes, devoid of thought and feeling. The QOF does not (and could never) include all medical conditions and the way they present in individual patients; nor capture the essence of the consultation, and the relationship between doctor and patient. ${ }^{6}$ Unintended consequences from the QOF's biomedical focus were anticipated, and are in evidence.

For one, quality can be substantially worse for those with conditions outside the framework, particularly the older people with complex medical problems. In face-to-face interviews in the English Longitudinal Study of Ageing, $75 \%$ of responders reported receiving endorsed quality of care for conditions included in the QOF, compared with $58 \%$ for those not. ${ }^{7}$ And the gap is likely to be widening. Across 18 practices, achievement against 15 indicators concerning depression and osteoarthritis increased by just one percentage point from 35\% to 36\% between 2003 and 2005, compared with a 16 percentage point improvement in incentivised indicators relating to asthma and hypertension. ${ }^{8}$

More worrying, however, is the effect of the QOF on the wider patient-centred and holistic strengths of general practice. You can never perform the gold standard of randomised control trials on every kind of patient GPs meet every day of the week, so two things remain vital. First, GPs must retain the freedom to use their experience and apply an ever-expanding base of sound research findings to individual patient care, particularly those with complex comorbidities. ${ }^{9}$ (The Department of Health, however, prefers to see exception reporting as 'unacceptable'). ${ }^{10}$ Second, values remain vital. Without attention to ideals such as kindness, caring, good communication, honesty, and, above all, trust, the doctor-patient relationship is nothing ${ }^{11}$ and clinical outcomes - dependent on many things that hinge on the doctor-patient relationship, including the initial recognition of patients' problems, more accurate diagnosis, and concordance with treatment advice - may well begin to flounder. ${ }^{12,13}$

Although inherently difficult to measure, a number of qualitative studies (and numerous anecdotes) point to the QOF having negative effects in this area. In one survey, for example, $75.9 \%$ of nurses reported feeling the framework was undermining the patient focus of the NHS. ${ }^{14}$ The root cause of this is that the QOF has put an agenda in the clinicians' heads that is not necessarily consistent with the patients' perceptions: 'There have been one or two occasions where I went through the cholesterol, the depression, the CHD, and everything else', one GP reported,,$^{15}$ '... and the patient said "Well, what about my foot then?", "What foot?", I replied'. As one exploration into the impact of the QOF concluded:

'The QOF scheme may have achieved its declared objectives of improving disease-specific processes of patient care ... but our findings suggest that it has changed ... the nature of the practitioner-patient consultation. ${ }^{15}$

This is unlikely to be desirable - as those taking part in Gillies et al's study well recognise. The traditional strength of general practice is precisely its conscious effort to be open-ended, inclusive, personal, and relationship-building. Whatever use the QOF has in driving clinical quality, we should forever be aware of unintended consequences and remember the wisdom of the German physician Martin $\mathrm{H}$ Fischer nearly 100 years ago: 'In the sick room', he said, '10 cents worth of human understanding can equal 10 dollars' worth of medical science'. 


\section{James D Gubb}

Director of Health Unit, Civitas: The Institute for the Study of Civil Society, London, SW1P 2EZ. E-mail: james.gubb@civitas.org.uk

\section{Competing interests}

The author has stated that there are none.

\section{REFERENCES}

1. Iliffe S. From general practice to primary care: The industrialisation of family medicine. Oxford: Oxford University Press, 2008.

2. Gillies JCM, Mercer SW, Lyon A, et al. Distilling the essence of general practice: a learning journey in progress. Br J Gen Pract 2009; 59: el67-e176.

3. Gubb J, Li G. Checking-up on doctors: a review of the Quality and Outcomes Framework for general practitioners. London: Civitas, 2008.

4. Campbell S, Reeves D, Kontopantelis E, et al. Quality of primary care in England with the introduction of pay for performance. N Engl J Med 2007; 357(2): 181-190.

5. Doran T, Fullwood C, Kontopantelis E, Reeves D. Effect of financial incentives on inequalities in the delivery of primary clinical care in England: analysis of clinical activity indicators for the quality and outcomes framework. Lancet 2008; 372(9640): 728-736.

6. Howie JG, Heaney D, Maxwell M. Quality, core values and the general practice consultation: issues of definition, measurement and delivery. Fam Pract 2004; 21 (4): 458-468.

7. Steel N, Bachmann M, Maisey S, et al. Self reported receipt of care consistent with 32 quality indicators. BMJ 2008; $337:$ a957.

8. Steel N, Maisey S, Clark A, Fleetcroft R, Howe A. Quality of clinical primary care and targeted incentive payments: an observational study. Br J Gen Pract 2007; 57(539): 449-454.

9. Glasziou P, Burls A, Gilbert R. Evidence-based medicine and the medical curriculum: the search engine is now as essential as the stethoscope. BMJ 2008; 337 : a1253.

10. Department of Health. Developing the Quality and Outcomes Framework: proposals for a new, independent process (Consultation Response and Analysis). London: TSO, 2009.

11. Halligan, A, The importance of values in healthcare, J R Soc Med 2008: 101: 480-481.

12. Starfield B, Shi L, Macinko J. Contribution of primary care to health systems and health. Milbank Q 2005; 83(3): 457-502.

13. Adam R. 'Personal Care' and general practice medicine in the UK: a qualitative interview study with patients and general practitioners. Osteopath Med Prim Care 2007 ; 1 : 13.

14. Healthcare Republic. Independent Nurse QOF survey. http://www.healthcarerepublic.com/news/GP/772416/Independent-Nurse-QOF-survey/ (accessed 2 Apr 2009).

15. Campbell SM, McDonald R, Lester H. The experience of pay for performance in English family practice: a qualitative study. Ann Fam Med 2008; 6(3): 228-234.

DOI: 10.3399/bjgp09X420644

2. WONCA Europe. The European definition of general practice/family medicine. London: WONCA Europe, 2005.

3. Royal College of General Practitioners. Being a general practitioner. Curriculum statement 1. London: RCGP Publications, 2007.

4. Postgraduate Medical Education Training Board. http://www.pmetb.org.uk/ (accessed 12 Mar 2009).

5. Statutory Instrument 291. The National Health Service (general medical services contracts) regulations 2004: Sch.3. London: HMSO, 2004.

6. Roland M. Linking physicians' pay to the quality of care - a major experiment in the United Kingdom. N Engl J Med 2004; 351(14): 1448-1454.

7. Gillies John CM. Getting it right in the consultation. Hippocrates problem; Aristotle's answer. Occasional Paper 86. London, RCGP Publications, 2005.

8. Mangin D, Toop L. The Quality and Outcomes Framework: what have you done to yourselves? Br J Gen Pract 2007; 57(539): 435-437.

9. Heath I, Hippisley-Cox J, Smeeth L. Measuring performance and missing the point? BMJ 2007, 335(7629): 1075-1076.

10. Freeman G. Up close and personal? Continuing pressure on the doctor-patient relationship in the QOF era. Br J Gen Pract 2006; 56(528): 483-484.

11. Davies P, Glasspool J. Patients and the new contracts. BMJ 2003; 326(7399): 1099.

12. O'Dowd A. Devolution in health policy is threatening unity of the NHS. BMJ 2008; 336(7638): 241.

13. Greer S. Analysis: devolution and divergence in UK health policies. BMJ 2009; 338: 78-80.

14. International Futures Forum. http://www.internationalfuturesforum.com/ (accessed 30 Mar 2009).

15. Lyon A (compiler). The fifth wave, searching for health in Scotland. Edinburgh: Scottish Council Foundation, 2003.

16. The Homeless World Cup Centre. http://www3.homelessworldcup.org/ (accessed 12 Mar 2009).

17. Brown J, Isaacs D. World café conversations. The world café: shaping our futures through conversations that matter. San Frasncisco, CA:
Berrett-Koehler Publishers Inc, 2005.

18. RCGP Scotland. The essence of general practice. An invitation to create the future. http://www.rcgp.org.uk/bookshop/info_ 0000000000EGP.html (accessed 31 Mar 2009).

19. Hart JT. The political economy of health care. London: Policy Press, 2006.

20. Watt GCM. The NHS at 60: time to end the fairy tale. Br J Gen Pract 2008; 58(552): 459-460.

21. Hunter D. The health debate: policy and politics in the 21st century. Bristol: Policy Press, 2008.

22. Beckstrom O, Brafman R. The starfish and the spider: the unstoppable power of leaderless organisations. London: Portfolio Books, Penguin, 2008.

23. Gregory S. Learning specialist skills for a generalist discipline. Editorial. Br J Gen Pract 2009; 59(559): 79-80.

24. McWhinney I. The importance of being different. The Pickles lecture. Br J Gen Pract 1996; 46(408): 433-436.

25. Royal College of Physicians. Report of a Working Party. The doctor in society: medical professionalism in a changing world. London: RCP London, 2005.

26. Greenhalgh T. Thirty years on from Alma-Ata: where have we come from? Where are we going? The Pickles lecture. Br J Gen Pract 2008; 58(556): 798-804.

27. Heath I. The mystery of general practice. London: Nuffield Provinical Hospitals Trust, 1997.

28. Delamothe T. A good QOFing whine. BMJ 2008; 337: 1173.

29. Hunter KM. Narrative, literature and the clinical exercise of practical reason. J Med Philos 1996; 21(3): 303-320.

30. Tarrant C, Colman A, Stokes T. Past experience 'shadow of the future' and patient trust: a cross sectional survey. Br J Gen Pract 2008; 58(556): 780-783.

31. Freidson E. Professionalism: the third logic. On the practice of knowledge. Chicago, IL: University of Chicago Press, 2001.

32. Iliffe S. From general practice to primary care: the industrialization of family medicine. Oxford: Oxford University Press, 2008. 